\title{
Relato final do II Seminário Nacional sobre Cursos de Graduação em Geologia
}

\author{
Campinas, abril de 2002
}

\author{
Celso Dal Ré Carneiro \\ Universidade Estadual de Campinas - UNICAMP
}

* Este documento deve ser referido como segue: Carneiro, C.D.R. 2005a. Relato Final do II Seminário Nacional sobre Cursos de Graduação em Geologia. Campinas, abril de 2002. Terræ Didatica, 1(1):55-63. <http:// www.ige.unicamp.br/ terraedidatica/>

Documento-base inédito: Carneiro, C.D.R. 2002a. Relato Final. II Seminário Nacional sobre Cursos de Graduação em Geologia. Campinas: Inst. Geoc. Unicamp. 12p. (Síntese das contribuições do II Seminário Nacional sobre Cursos de Graduação em Geologia, Campinas, 24.04 a 26.04.2002).

1 Consta no site do MEC, em http://www.mec.gov.br/ Sesu/diretriz.shtm, conforme acesso efetuado em 04.06.2002, a observação > "As Diretrizes Curriculares abaixo, que ainda estão em exame no CNE, são propostas que necessitam aguardar sua aprovação e homologação". Existe ali referência idêntica, ou equivalente, desde meados de 2001.

\section{Introdução}

O II Seminário Nacional sobre Cursos de Graduação em Geologia, promovido pelo Instituto de Geociências da Unicamp e pela Sociedade Brasileira de Geologia, realizou-se entre os dias 24 e 26 de abril de 2002 nas dependências da Universidade Estadual de Campinas - UNICAMP. O encontro teve o apoio do Instituto de Geociências da UFBA, Companhia Baiana de Pesquisa Mineral (CBPM), Conselho Federal de Engenharia, Arquitetura e Agronomia (CONFEA), Conselho Regional de Engenharia, Arquitetura e Agronomia de São Paulo (CREA-SP), Sindicato dos Geólogos no Estado de São Paulo (SIGESP) e Federação Nacional dos Geólogos (FEBRAGEO).

Compareceram 18 (dezoito) das 19 (dezenove) escolas de Geologia do Brasil, representadas pelos respectivos coordenadores de cursos, coordenadores associados e alguns diretores. Durante três dias discutiram-se questões centrais que afetam a realidade atual dos cursos de Geologia, cujos resultados estão sintetizados neste relato, elaborado sob responsabilidade exclusiva do Relator. São apresentadas propostas, recomendações, decisões e temas identificados para posterior ação conjunta. Procurou-se respeitar algumas particularidades do debate, quando pertinente (itens 7,8 e 11, a seguir), pois entende-se que a inclusão desses dados, recolhidos pelos relatores das diversas sessões, reflete mais adequadamente o que foi discutido.

O tema prioritário para debate foi a proposta de diretrizes curriculares dos cursos de Geologia, sobretudo em função da morosidade da aprovação pelo $\mathrm{MEC}^{1}$ da proposta existente e devido à não-consideração do documento final do I Seminário Nacional sobre Cursos de Graduação em Geologia, realizado na cidade de Salvador em 2001. A análise detalhada de ambos os textos (aqui referidos como Mesquita et al. 2001 e MEC 1999 [Comissão de Especialistas]), possibilitou aprimorá-los, resultando em novo documento, a ser encaminhado ao MEC para avaliação. 


\section{Temas discutidos}

Os principais temas discutidos foram:

- a representatividade das decisões do grupo que se reuniu em Campinas;

- as Diretrizes Curriculares;

- a transformação dos currículos atuais por meio dos projetos pedagógicos de cursos;

- o ensino à distância;

- os cursos seqüenciais;

- a carga horária mínima exigida de trabalhos de campo;

- a situação atual do Centro de Geologia Eschwege;

- o estágio supervisionado;

- o intercâmbio entre instituições para alunos no final dos cursos de Geologia;

- a necessidade de disciplina básica de Ciências da Terra em cursos de graduação relacionados ao ambiente natural;

- o perfil desejado para a licenciatura a ser oferecida aos graduandos em Geologia;

- as atribuições profissionais, mercado de trabalho, CREAs-CONFEAs.

\section{Representação}

Constitui importante decisão do evento a criação do Fórum Nacional de Cursos de Geologia, formado pelas IES ${ }^{2}$ cujos representantes vieram ao II Seminário - e pelas respectivas universidades -, devendo ser convidado ainda o curso de Geologia da UFPE, que não enviou representante. O Fórum Nacional de Cursos de Geologia deverá abrigar, de forma organizada e contínua, discussões sobre os problemas inerentes à formação de geólogos e seus instrumentos de execução, garantindo representatividade, bem como a necessária formalidade, perante o MEC e demais órgãos, às proposições e diretrizes estabelecidas pelo colegiado.

Um dos objetivos do Fórum é a permanente troca de informações entre os coordenadores de curso. Dentre as alternativas analisadas de formalização do Fórum, algumas envolvem reconhecimento dessa instância pelos institutos e departa-

2 IES: Instituição de Ensino Superior. mentos (quer pelos respectivos conselhos departamentais, quer pelas congregações). Em relação a membros participantes, foi recomendado que se discutisse nas diferentes unidades se deveria haver participação, além dos coordenadores, que são membros natos, da coordenação dos cursos de pósgraduação, diretorias, e eventuais membros discentes de graduação.

Foi aprovada consensualmente a idéia de que o fórum constitui instrumento ativo para se buscar mudanças junto aos órgãos de decisão. O próximo encontro do Fórum será sediado em Belém, PA, no final de maio de 2003. A ação junto ao MEC, para se encaminhar a documentação aprovada sobre diretrizes curriculares, será conduzida imediatamente, pelos professores: Mesquita (UFBA); Edi (UNB) e Celso (UNICAMP).

\section{Diretrizes Curriculares}

A partir da retomada dos pontos consensuais aprovados na reunião de Salvador, foram discutidos os seguintes temas: (a) obrigatoriedade do atendimento das diretrizes ou existência de certa flexibilidade curricular; (b) dúvida sobre as diretrizes: preservam na prática o antigo Currículo Mínimo?; (c) conciliação entre conteúdos previstos e as diversas disciplinas; (d) problema de taxas de evasão no ciclo básico e, neste ciclo, falta de integração com conteúdos típicos de Geologia. Outros temas debatidos foram os projetos pedagógicos de cursos; a alternativa de ensino à distância na área de Geologia e, finalmente, a carga horária mínima exigida para trabalhos de campo.

Após os debates, concluiu-se que a divergência entre a proposta da comissão de especialistas do MEC e a do I Seminário não é significativa a ponto de se postergar reformas curriculares agora, embora seja recomendado aguardar a aprovação final do MEC. Todavia, podem ser realizadas pequenas alterações para atender a situações emergenciais, como eventuais pressões sofridas pelos cursos para alterações curriculares urgentes (por parte do MEC ou das próprias reitorias).

Deve ser planejada e incluída na programação dos cursos uma carga horária mínima de atividades de campo, que pode estar contida, ou não, na carga horária de diferentes disciplinas; o nível mínimo requerido é de $20 \%$ do total do curso (por exemplo, 600 horas para um curso de 3000 horas). 


\section{Estágios de campo no Centro de Geologia Eschwege}

Estimulada pelo alto interesse das diversas IES, desenvolveu-se discussão sobre o Centro de Geologia Eschwege que, historicamente, tornou-se vinculado à UFMG e contou, a partir do início da década de 80, com repasses de verbas do CNPq. Alguns presentes registraram que, nessa época, a UFMG assumiu a administração do centro desde que fosse mantido o compromisso de se continuar a oferecer os estágios de campo.

Estágios de campo no Centro de Geologia Eschwege (CGE) são absolutamente indispensáveis para a formação dos geólogos brasileiros; muitas IES incluem atividades de campo no CGE em suas programações anuais; até mesmo aquelas que não as colocam no calendário oficial incentivam os alunos a realizar estágios extracurriculares em Diamantina, aproveitando as instalações e a infraestrutura disponível. Foi decidido que, após o II Seminário, seriam coletados mais dados sobre problemas atuais do CGE.

Informações recentes obtidas por este Relator ${ }^{3}$ junto ao Prof. Dr. Antônio Gilberto Costa, Diretor do IGC/UFMG, são a seguir expostos:

- Os recursos que são repassados pelo CNPq dependem do envio anual de solicitação na forma de projetos de pesquisa que, além dos cortes, estão sempre na dependência da existência de recursos extras. Não existe nenhum compromisso com a liberação de um certo volume de recursos mínimos, cabendo à UFMG complementá-los.

- É necessário garantir recursos mais permanentes do CNPq na parte que se refere à alimentação, manutenção dos veículos, combustível, equipamentos, material de escritório, apoio aos estudantes, bolsas PIBIC etc. A forma desejável - conforme salientado pelo próprio CNPq - é a de um convênio, considerado prioritário, e de termos aditivos, nos quais a liberação de recursos fosse regular.

- Da mesma forma, é necessária a previsão de recursos para modernização dos laboratórios didáticos, alguns dos quais não sofrem atualização desde que a UFMG assumiu a administração. O microscópio, os estereoscópios de espelho e as bússolas ou foram transferidas pelos alemães, ou foram adquiridas logo no início da instalação do centro, há 23 anos.
- A formalização de um convênio entre a UFMG e o CNPq, a recomposição de um conselho, com representação da UFMG, do IGC, do CGE, do CNPq, das Universidades envolvidas e da SBG, como sugerido nos termos do Protocolo de Cooperação de 1985, mostra-se como a alternativa para manutenção do contato entre todas as instituições envolvidas, para a garantia da manutenção das atividades do CGE e para a necessária aquisição de equipamentos novos.

- A infraestrutura do CGE (instalações diversas, salários de funcionários, aquisição de veículos, custos com luz, telefone, água, etc.) vem sendo mantida pela UFMG que, a exemplo das demais universidades, também sofre restrições progressivas devido aos cortes orçamentários para Educação.

- A decisão da UFMG de centralizar em Belo Horizonte os professores que antes residiam em Diamantina permitiu maior integração destes, mas fêz aumentar muito os deslocamentos, fato que obriga a universidade a custear mais diárias de campo.

- Decorre desse conjunto de fatores, por exemplo, a insuficiência de recursos para custeio de diárias, já que o valor global destas aumentou muito.

Ademais, informa-nos o Prof. Gilberto que os custos das diárias podem ser minimizados, por meio da participação no programa de professores de outras universidades, sendo que alguns já acompanham os estudantes nos deslocamentos para Diamantina, mas não participam da orientação. Sob a supervisão dos docentes da UFMG, os colegas das universidades envolvidas poderiam assumir parte da orientação. Além da redução de custos para a UFMG, isto permitirá maior integração entre docentes de diversas escolas. As universidades não teriam que repassar recursos para a UFMG, bastaria que continuassem a enviar um professor para participar do programa - ou passassem a adotar tal prática, no caso das que ainda não o fazem.

A recomendação de que os coordenadores de curso ajudem a pressionar o CNPq para a assinatura do convênio coincide com a decisão aprovada pelo II Seminário de se manter a parceria com o

3 Nota do Relator: O Fórum havia previsto que a UFMG encaminharia, após o II Seminário, informações adicionais para subsidiar os trabalhos. Uma vez que o maetrial não chegara a tempo, fizemos o contato, extremamente oportuno, para evitar descompasso de informações. 
CNPq com aumento de verba, sem prejuízo de que sejam abertas novas parcerias, como por exemplo com a ANP, ANA ou ANMIN.

Este breve relato conclui com a recomendação de que cada coordenador de curso envie um documento ao CNPq e à Reitoria da UFMG, com cópia para a diretoria da UFMG, reafirmando a declaração da importância do CGE para a formação dos geólogos brasileiros.

\section{Estágio Supervisionado}

Foi consensual no II Seminário o reconhecimento do importante papel do estágio dos graduandos para aprimorar sua formação profissional. Nos debates, considerou-se desejável a inclusão da disciplina (ou atividade) denominada Estágio Supervisionado, de caráter obrigatório ou não, como parte integrante do elenco das disciplinas dos cursos de graduação em Geologia. O que diferencia essa disciplina (ou atividade) das demais é ser uma interação da escola com a empresa; tal interação proporciona ao estudante mais conhecimentos e experiência no campo profissional. Uma vantagem fundamental é a verificação prática de que a realidade de uma empresa está voltada para a qualidade e produtividade.

A disciplina (ou atividade) Estágio Supervisionado pode ter, como sugestão, uma carga horária total entre 120 horas a 160 horas; isso permite que a atividade seja realizada de forma concentrada, na empresa, no período de recesso de aulas escolares e durante 30 dias, ou eventualmente dispersa no semestre, com carga horária variando de 9 a 10 horas semanais.

\section{Intercâmbio entre instituições}

\section{Intercâmbio de alunos}

Foi reconhecido por unanimidade que a prática do intercâmbio entre instituições para alunos no final dos cursos de Geologia, em determinadas ênfases previstas nas Diretrizes Curriculares e que, eventualmente, possam não estar contempladas nas unidades de origem viabilizará significativa troca de experiências e aprimoramento dos futuros profissionais. Entretanto, para que seja possível avançar nessa direção e dar início a futuros acordos de cooperação, é necessário levantar os pré-requisitos existentes e eventuais exigências formais das diferentes escolas.
Dessa forma, recomenda-se que os coordenadores de curso avaliem quais as exigências e os dispositivos existentes internamente em suas respectivas universidades para proporcionar intercâmbio de alunos destes cursos com outros, para desenvolver os conteúdos e adquirir habilitações nas áreas temáticas.

\section{Intercâmbio de materiais didáticos}

Foi salientado que constitui prioridade para os cursos de Geologia a promoção do intercâmbio interinstitucional de materiais didáticos em geral (livros, softwares, apostilas etc. produzidos e disponíveis).

Para viabilizar essa iniciativa, decidiu-se recomendar, em uma primeira etapa, que os coordenadores realizem amplo levantamento dos materiais existentes, dando a esses dados a maior divulgação possível. Incluem-se nesse levantamento todos os recursos didáticos disponíveis nos diferentes cursos, tais como livros, software, apostilas produzidas, vídeos e coleções didáticas de amostras.

\section{Intercâmbio de informações pedagógicas e curriculares. Ensino à distância}

Foi proposto criar um site específico do tipo adotado em ensino à distância, tal como o oferecido pelo TelEduc, com acesso para os componentes do fórum, onde seriam instalados todos os arquivos deste fórum, bem como novas inserções de documentos por parte dos coordenadores. Foi igualmente sugerido que a difusão da informação devesse ser mais ampla, por meio de um site ou um grupo de e-mails. Ambas as idéias são compatíveis, ou seja, uma não elimina a outra, devendo-se dispor de espaço específico para intervenção dos componentes do fórum, enquanto os informes devem ser encaminhados à comunidade por diversos meios. Na discussão sobre o TelEduc, as questões operacionais serão encaminhadas por uma comissão composta por Pina, Celso e Edi que prepararão a reunião de trabalho no Congresso de Geologia de João Pessoa, bem como encaminharão providências sobre o TelEduc.

\section{Cursos Seqüenciais}

O Fórum considera que, diante das especificidades do campo de conhecimento, a modalidade de cursos seqüenciais não constitui alternativa válida para oferta pelas universidades. Assim, sugere que sejam introduzidos critérios muito rígidos para apreciação e eventual aprovação de propostas dessa natureza. 


\section{Atribuições, mercado de trabalho, CREAs-CONFEAs}

O desenvolvimento do tema orientou-se para a análise de algumas preocupações levantadas pelo Fórum, culminando em algumas recomendações:

- A importância do estudo de tendências de absorção de profissionais pelo mercado como elemento de orientação pedagógica para os cursos de geologia.

- Ação integrada entre a academia, os órgãos de classe e entidades sindicais na preservação/ampliação da empregabilidade.

- O dilema entre a formação generalista ou especializada no contexto das novas perspectivas (possibilidades) de atuação técnico-científica do geólogo.

\section{Perfil do Geólogo}

A reunião reforçou a tese, debatida em Salvador (Sobreira 2005), da necessidade de um profissional geólogo com perfil mais adequado à atualidade, que deverá ter as seguintes características:

- Profissional generalista, com visão ampla das geociências.

- Sólida formação básica e constante atualização científica, capaz de adaptar-se rapidamente às mudanças e às novas necessidades do mercado.

- Compreensão da Geologia privilegiando a caracterização dos processos.

- Ênfase na percepção de problemas, sua análise e oferecimento de soluções.

- Percepção da realidade atual e das demandas sociais.

- Capacidade de interação e trabalho em conjunto com profissionais de outras áreas (engenharia, arquitetura, economia, etc.)

- Capacidade de gestão de projetos, pesquisa e empreendimentos.

\section{Mercado de Trabalho}

A realimentação das escolas pela experiência acumulada dos ex-alunos é um mecanismo útil para aproximar a prática profissional nas ciências geológicas e melhorar a relação entre a estrutura teórica de ensino e pesquisa com a prática profissional, e para atender às novas demandas (Sobreira 2005), sejam elas específicas ou interdisciplinares.
Foi lembrado que a Febrageo procurou este fórum afirmando que pretende fazer um levantamento da situação dos geólogos formados em nossas escolas. Foi proposto que os coordenadores alimentem um banco de dados com os nomes de todos os formados no país. Ainda que em algumas escolas o número de formados possa ser menor que outras, as associações de classe atuantes podem facilitar muito o trabalho. Sugeriu-se que se façam cruzamentos entre dados da SBG, dos CREAs de todo o país, de modo a somar informações. Decidiu-se elaborar um questionário, partindo das experiências já feitas em Belém e Natal, mas as alternativas não foram consolidadas:

- UNESP propõe que se faça um perfil do estudante que agora está nas universidades;

- UFPR pretende disponibilizar material metodológico utilizado em suas pesquisas sobre a atuação dos seus ex-alunos.

- Os dados levantados serão repassados para a Febrageo, que tem interesse em dar andamento a esse levantamento.

- A Febrageo terá um encontro em maio, em Brasília, e solicita que um representante deste fórum apresente lá um relato sobre temas e resultados deste seminário. Foi designada a Profa. Edi Guimarães (UnB).

\section{Divulgação das Geociências}

Com a finalidade de dar mais visibilidade à carreira do geólogo, anotaram-se várias contribuições:

- UFMT propõe que o fórum proponha uma intencionalidade das associações regionais, estaduais, no sentido de dar visibilidade ao trabalho do geólogo, citando que em MT a ABAS leva geólogos para diversas cidades do interior para discutir água subterrânea, reunindo grandes quantidades de pessoas em cada cidade; ocupar também espaços nos noticiários.

- UFRJ lembra que se deve buscar o envolvimento e a ação da SBPC, no projeto chamado Ciência na Escola, sendo que já se conseguiu nesse projeto platéias de mais de mil pessoas em escolas - a dificuldade se situa na falta de pessoal disponível.

- Outro espaço interessante é a revista Ciência Hoje das Crianças, que é gratuitamente distribuída em escolas públicas de todo o país, numa tiragem de 100 mil exemplares, sendo esse 
um espaço fantástico para divulgação geológica.

- UNICAMP lembra que já há sugestão para que a série Ciência Hoje na Escola inclua dois novos temas geológicos em seus próximos volumes, e se propõe a encaminhar a todos o material que tem sobre isso, aguardando sugestões.

- UFRJ afirma que a SBPC não coloca temas de uma mesma área em números sucessivos da revista - exceto temas de Biociências -, sendo preciso fazer um trabalho para convencê-los da variedade de temas que se pode trabalhar, para depois inserir temas de geociências em maior número de exemplares.

- UNICAMP entende que contatos para a participação de geólogos em palestras já podem ser feitos.

- UnB lembra da importância de se enfatizar a presença da geologia no cotidiano das pessoas.

- UNICAMP fala sobre trabalho de bolsista que está levantando sites de geologia, cuja divulgação poderia ser muito interessante ${ }^{3}$.

- UFRJ fala da importância de se publicar livros para-didáticos, e se propõe a contactar a editora Interciência, acrescentando a informação de que o MEC pode comprar lotes imensos de livros, dependendo de decisões políticas, com forte influência da ação das associações de classe, de diversas entidades.

- UA descreve um embrião de museu nos corredores da escola e discorre sobre a ida de alunos do curso de Geologia aos colégios e sobre a vinda dos estudantes do ensino básico à universidade, principalmente nos períodos de realização de feiras de ciências.

- UFRGS relembra a proposta feita neste seminário de se enfatizar que os exames vestibulares contenham questões mais diretamente vinculadas a geociências, uma vez que esses conteúdos se encontram nos PCNs vinculados às diversas áreas das ciências.

\section{Disciplina básica de Ciências da Terra}

O Fórum aprovou a seguinte recomendação: Considerando-se:

- a ausência de conteúdos geológicos em cursos de graduação relacionados ao estudo do meio-ambiente;

3 Nota dos Editores: o trabalho publicado conforme a referência: Carneiro, C.D.R.; Henrique, A. 2005. Análise de sites em geociências e difusão de materiais didáticos na internet. Geol. USP, Publ. Espec., v.3, p. 57-70, setembro de 2005.
- a contribuição da Geologia para o conhecimento científico da natureza;

- a característica independente da Geologia em relação a outras ciências, como Geografia Física, Química e Física;

- a importância da Geologia no momento histórico vivido pela humanidade, sobretudo pelos problemas de recursos naturais e equilíbrio ambiental;

- a Geologia como perspectiva integradora dos conhecimentos científicos da natureza;

Sugere-se:

- Que os cursos de graduação relacionados ao estudo do meio-ambiente incluam conteúdos elementares de Geociências e dos processos da natureza, para habilitar esses profissionais a interagir, em perspectiva interdisciplinar, com outros profissionais de Ciências da Terra.

A discussão sobre conveniência de se apontar uma carga horária mínima para tal disciplina e sobre conteúdos mínimos que devam ser trabalhados resultou em muitas sugestões. Embora seja essencial que se expressem claramente os conteúdos que deverão ser trabalhados por estudantes de Engenharia Ambiental, por exemplo, foi ponderado que qualquer profissional das áreas ambientais deva ter formação que lhe permita interação com os demais geocientistas; assim, seria inadequado amarrar demasiadamente o currículo. Considerando que tais profissionais devem possuir conhecimentos elementares que lhes permitam o trabalho interdisciplinar, decidiu-se divulgar as atuais ponderações do fórum, para simplesmente apontar a necessidade da disciplina, sem outras definições, até que a idéia esteja mais amadurecida.

\section{Avaliação de livros didáticos}

O Fórum Nacional dos Cursos de Graduação em Geologia, reunido no período de 24 a 26 de abril de 2002, em Campinas-SP, durante a realização do II Seminário Nacional sobre Cursos de Graduação em Geologia, no qual foram discutidos vários aspectos relacionados ao ensino de Geologia, decidiu encaminhar correspondência, na forma que se segue:

Considerando:

- o exposto nos (Artigos, parágrafos dos PCN) que se referem aos conteúdos geológicos a serem desenvolvidos no Ensino Médio; 
- que os conteúdos supracitados não são ministrados, na absoluta maioria dos casos, por professores que detenham o conhecimento específico sobre os mesmos;

- que os conteúdos em Geociências presentes nos livros didáticos de Biologia, Física e Química contêm, muitas vezes, equívocos ou inadequações;

- que estes conteúdos são fundamentais para que sejam atingidos os objetivos expostos nos (artigos, parágrafos dos $\mathrm{PCN}$ ) ;

- que estes mesmos conteúdos podem ser responsáveis pelo despertar de vocações para a formação de futuros profissionais em Geologia/Geociências,

\section{Solicita-se:}

- que a Comissão do MEC encarregada da avaliação dos livros didáticos dirigidos ao Ensino Médio passe a contar com a participação ou assessoria de um representante da comunidade geológica.

\section{Licenciatura em Geologia}

É desejável que as coordenações de curso acompanhem as discussões sobre as licenciaturas para se estabelecer uma estratégia de inserção das Geociências no ensino básico. Surgiram, nos debates, alguns questionamentos sobre a possibilidade de se formar um profissional para o qual não haja mercado de trabalho:

- USP afirma que, se um aluno do bacharelado fizer disciplinas disciplinas optativas e eletivas na área de pedagogia, ele poderá ter a carga horária e disciplinas que lhe permitam requerer o certificado da licenciatura.

- UFRGS informa que, no curso de Biologia, o aluno segue até o final do curso e opta pela modalidade, ou faz as duas modalidades, ou seja, bacharelado e licenciatura.

- UFMT discorda da forma híbrida de formação de bacharel/licenciado, argumentando que o curso de formação de professores deve ter essa característica desde seu primeiro momento; o licenciado em Geociências deverá estar habilitado para ensinar Ciências no ensino fundamental e, eventualmente, conteúdos de geologia nas diferentes áreas de ciências do ensino médio

- Esses argumentos são importantes para que se pense em, no futuro, introduzir a disciplina Geo- logia no ensino médio. Foram discutidas as possibilidades de um aluno licenciado poder cursar o bacharelado, solicitando aproveitamento de estudos - caso haja uma certa similaridade entre cursos, o licenciado poderia ser matriculado, por exemplo, no terceiro ano do bacharelado.

- Outro modo de compreender a questão é a alternativa de permitir licenciatura em Geografia, para graduados em Geologia (Carneiro 2002). Esta possibilidade está sendo aberta na Unicamp, caso geólogos formados decidam reingressar para cursar a modalidade licenciatura em Geografia ${ }^{4}$.

\section{Comissão de Especialistas do MEC}

No último dia de reuniões do Fórum, foi convidado o Prof. Bernardino Figueiredo, membro da Comissão de Especialistas do MEC.

O convidado discorreu sobre a comissão de notáveis que elaborou uma proposta de Diretrizes Curriculares para os cursos de Geologia. No ano 2000 essa comissão foi substituída pela comissão de especialistas R.A. Fuck, Bernardino Figueiredo e Prof. Cândido (UFPA), sob coordenação de Fuck. Destacou que falará neste encontro em termos absolutamente pessoais, sem refletir a avaliação da comissão da qual faz parte e que, em sua opinião, reuniu-se poucas vezes, produziu muito pouco e está praticamente parada - a greve das federais afetou o MEC e a atual direção fora bastante arranhada nesta greve -, mas situou que o imobilismo não é só do MEC; tem sido próprio da comunidade de geociências nas últimas décadas. Salientou ainda: "convivendo com outras comissões, percebe-se que somos privilegiados, com 19 cursos, sendo somente $1 \mathrm{em}$ escola privada - são 19 cursos excelentes - os cursos de geologia são, comparativamente aos demais cursos, ilhas de excelência em termos, por exemplo, de capacitação docente. Somente a UFMT não tem curso de pós-graduação em Geologia. A LDB e o documento das novas diretrizes, mais o que aqui está sendo produzido, são documentos suficientes para subsidiar possíveis reformas curriculares,

4 Nota do Relator: Novas regras, aprovadas pela Comissão Central de Graduação em 6 de junho de 2002 permitem o retorno de alunos, mediante aprovação da Coordenadoria do curso, para complementar outra habilitação ou modalidade do curso em que se graduou, ainda que envolva períodos distintos desse mesmo curso. Isso permite que, na prática, os alunos de geologia incluam em seus planos cursar a outra modalidade. 
permitindo que as escolas se diferenciem umas das outras", afirmou Bernardino.

O convidado prosseguiu: "no documento de geologia foi adotado o mesmo critério adotado para os cursos de engenharia. A proposta de MT, com 3100 horas, está exatamente dentro do esperado. A carga horária não inclui a carga horária de campo. Os professores se estressam dando todo um conteúdo, sendo que o aproveitamento do estudante é baixo, pois o aluno sobrecarregado de aulas não tem tempo para estudar. Os alunos têm que saber que estão numa universidade, têm que ter tempo para isso, e também para estudar e, conseqüentemente, aumentar seu rendimento. Diminuição de carga horária associada a aumento de atividades correlatas é o que vai contribuir para a formação do profissional mais apto para a sociedade de hoje. O aluno precisa desenvolver sua habilidade de aprender, para que possa estudar todo o resto da vida. Os profissionais precisarão cada vez mais voltar à universidade durante sua vida profissional". Concluindo, o professor Bernardino assinala que "não é possível para uma escola ser muito boa em todas as áreas do conhecimento geológico". Abertos os debates, houve os seguintes comentários:

- UNB fala da reforma curricular feita naquela escola, e ressalta que a dificuldade muitas vezes se encontra em como romper as deficiências que os alunos trazem no sentido de saber aprender.

- UFOP questiona sobre a carga horária, em um semestre com 100 dias letivos e, portanto, com 20 semanas, o que faz subir demasiadamente a carga horária.

- UFMT fala sobre a necessária mudança de mentalidade dos professores para atuar com uma menor carga horária, pois é preciso elaborar mais as estratégias de preservação efetiva do tempo do aluno, que deve realmente "aprender a aprender".

- Bernardino fala sobre questionamento da UFMT relativo à diminuição das cargas de ciências. Um aluno com boa base de ciências será aquele com mais facilidade para interagir com as demais áreas. Mas, da forma como muitas vezes isso é trabalhado, muita carga de ciências acaba por se tornar inútil. O aluno estará mais motivado a aprender ciências quando perceber que aquilo será uma ferramenta verdadeiramente útil para ele. Portanto, ciências pode ser pensada para um momento mais avançado do curso. Talvez seja o caso de se possibilitar que o aluno tenha acesso a cursos das áreas de ciências nos últimos períodos do curso.

- Celso assinalou que a leitura da pauta deste simpósio, com as respectivas posições definidas, seriam a agenda inicial da reunião de trabalho em João Pessoa.

- Bernardino esclarece que a comissão tinha intenção inicial de propor ao MEC a realização de uma avaliação de todos os cursos, pois há casos em que a avaliação existente foi feita há 42 anos. Com base nos resultados, a comissão poderia apontar problemas específicos para solicitar do MEC providências no sentido de sanar problemas. Isso, entretanto, não foi feito.

\section{Conclusões e recomendações finais}

\section{Avaliação e proposições do II Seminário}

O II Seminário foi considerado altamente positivo pelos participantes, em vista da maturidade e, sobretudo, pelas modificações previstas pelas quais poderão passar os cursos de Geologia. As mudanças necessárias em decorrência das Diretrizes despertam preocupação, mas as propostas e a troca de experiências foram essenciais para que sejam superados os eventuais impasses. Deve ser enfatizada a crescente participação de coordenadores dos cursos de geologia do País. O encontro de Campinas foi essencial para consolidar a representatividade do evento anterior, em Salvador. Os cursos de Geologia contam com espaço permanente de discussão de seus problemas e, ao mesmo tempo aumentou-se ainda mais o peso político das deliberações.

\section{Recomendações especiais do Fórum}

As principais recomendações dos participantes para garantir a continuidade dos trabalhos e consolidar a integração entre os cursos de Geologia do Brasil são:

- Reencaminhamento ao MEC do texto de sugestões para alteração do documento oficial sobre as diretrizes curriculares para os cursos de Geologia.

- Organização de novo encontro, a ser realizado em Belém, em maio de 2003, havendo uma reunião de trabalho em João Pessoa, no mês de setembro próximo. 
- Realimentar as escolas, fazendo uma aproximação com ex-alunos;

- Ação junto à sociedade;

- Valorização da Geologia no ensino fundamental e médio.

\section{Próximos encontros do Fórum}

Algumas orientações foram sugeridas para os próximos encontros do Fórum; para a próxima reunião de trabalho em João Pessoa, será encaminhado convite ao MEC para que participe, e o Fórum convocará formalmente Coordenadores de Cursos para essa reunião.

- Definição de uma agenda de temas a serem abordados em conjunto pelos diversos cursos (evasão escolar, criação de cursos seqüenciais, reformas curriculares, etc.)

- Na próxima reunião presença de representação da direção das unidades (de preferência o diretor);

- Criação de uma rede de comunicação à distância de forma a facilitar a interação entre os cursos e seus problemas gerais.

- Aprimoramento, atualização e disponibilização de banco de dados sobre currículos de cursos brasileiros, na homepage do Fórum.

- Apontar no fim do evento o rumo do próximo;

- Centrar as discussões com menos palestras;

- Inserção de uma palestra pelos alunos;

- Mesa Redonda no Congresso sobre Diretrizes Curriculares (MEC, Comissão de Especialistas, Fórum) com chamada oficial na $3^{\text {a }}$ circular.

\section{Agradecimentos}

No encerramento dos trabalhos, foram feitos agradecimentos às universidades envolvidas, que proporcionaram os meios para deslocamento e participação dos diversos representantes. Foi sublinhado como decisivos para o êxito do encontro os apoios da sociedade científica, sindicato e associações profissionais mencionados na Introdução deste relato. Agradecimentos são devidos à Unicamp, que sediou o evento, e à UFBA, que auxiliou a coordenação dos trabalhos, além do apoio financeiro da Companhia Baiana de Pesqui- sa Mineral (CBPM), Conselho Federal de Engenharia, Arquitetura e Agronomia (CONFEA), Conselho Regional de Engenharia, Arquitetura e Agronomia de São Paulo (CREA-SP). Finalmente, cabe registrar o grande empenho, profissionalismo, espírito de equipe e eficácia dos coordenadores participantes, palestrantes, moderadores e relatores, que souberam estimular o debate e, ao somar esforços para intercambiar experiências, iluminaram as alamedas e caminhos que levarão, no futuro próximo, ao fortalecimento dos cursos brasileiros de graduação em Geologia.

\section{Referências Bibliográficas}

Carneiro, C.D.R. 2002. Licenciatura em Geografia para cursos de graduação em Geologia? Campinas: Unicamp. Abril, 2002. (apresentação, II Seminário Nacional sobre Cursos de Graduação em Geologia)

Mesquita F.J.G.; Artur, A.C.; Lazzarotto, A.; Misi, A.; Leipnitz, B.; Barros, C.E.; Carneiro, C.D.R.; Tubbs Filho, D.; Assis, F.P.; Abreu, F.A.M.; Sobreira, F.; Moura, M.A.; Toledo, M.C.M.; Souza, M.A.T.A. de; Costa, R.D.; Zouain, R.N.A.; Menegat, R.; Nadalin, R.J.; Santos, R.A.A. dos; Vasconcelos S.M.S.; Marques T.M.; Neri, T.F.O.; Dias, V.M.; Souza Z.S. de. 2001. Sugestões de Alteração para a Proposta de Diretrizes Curriculares para os Cursos de Graduação em Geologia e Engenharia Geológica. Salvador: Inst. Geoc. UFBA. 9p. (doc. inédito, elaborado com base nas contribuições do I Seminário Nacional sobre Cursos de Graduação em Geologia, Salvador, 30.05 a 01.06.2001).

Ministério da Educação. Secretaria de Educação Superior. Coordenação de Comissões de Especialistas de Ensino. Comissão de Especialistas de Ensino de Geologia e Oceanografia. Gomes, N.S.; Landim, P.M.B.; Fuck, R.A.. 1999. Diretrizes curriculares para os Cursos de Graduação em Geologia e Engenharia Geológica. Brasília: MEC. (em http://www.mec.gov.br/Sesu/diretriz.shtm, conforme acesso em 04.06.2002). (Sub-Comissão de Especialistas de Ensino de Geologia, Portaria no $146 \mathrm{SESu} / \mathrm{MEC}$ de 10 de março de 1998).

Sobreira, F. 2005. Relato Final do I Seminário Nacional sobre Cursos de Graduação em Geologia. Terrce Didatica, 1(1):51-54. (Publ. de doc. inédito: Sobreira, F. 2001. Síntese das contribuições do I Seminário Nacional sobre Cursos de Graduação em Geologia, Salvador, 30.05 a 01.06.2001. Ouro Preto: Inst. Geoc. UFOP. 4p.). 